my hands in several waters, with solution of chloride of lime, and although I delivered the woman, I was careful to make as few examinations as possible. This case, it will be understood was attended on the 23rd of January. The woman had some slight symptoms of peritonitis on the 25th; her pulse was very frequent, and there was severe pain with some tenderness. She had some saline aperient medicine, with fomentations, and did well.

As soon as I could be released from $\mathrm{my}$ attendance on Mrs. T. T.,-for I did not think it prudent to allow my substitute to pass the catheter for her,-I went into Leicestershire for a fortnight. I am happy to say that $I$.have not seen a case of malignant puerperal fover since, though I have, as may be supposed, seen several cases of simple peritonitis.

I may be allowed to observe upon the above accurate detail of facts, that if it be conceded that my attendance on the case of erysipelas was the cause of this formid. able malady getting into my practice, which, painful as the thought may be, I think was the case, it seems probable :-

First. That as the cases attended on the 6th and 7th of January, recorered without the appearance of any unfarourable symptoms, a form of erysipelas, which may supsequently in its malignant and almost putrid stage originate puerperal fever, will not do 80 in its early stage.

Secondly. That as the disease did not come on in the the same patients, notwithstanding my risiting them after attending the erysipelatous case when the symp. toms had become formidable, the merely taking a lying in woman by the hand will not originate the disease.

Thirdly. That as the woman attended on the 15th of January recovered without any symptoms of the malady, although I might at the time, be supposed to be tainted with both the erysipelas and the puerperal disease of Mrs. T. T., it requires something more than a mere visit to a parturient woman to communicate the disease from one puerperal patient to another.*

Fourthly. That, bearing in mind the above enppositions, the circumstances immediately preceding and accompanying the attendances on both Mrs. T. T. and Mrs. R. B., go to prove that it requires actual contact of the accoucheur's infected hand with the mucous membrane of the ragina, both to originate and communicate the disease. (Query-would not the heai and pain of the vulva in the first case confirm or strengthen this supposition?)

Fifthly. That the slight manner in which the disease appeared in the woman attended on the 23rd, (notwithstanding I was still passing the catheter daily for Mrs. T. T., and had but just returned from a risit to $\mathrm{Mrs}$. R.B., the latter being at the time almost typhoid,)

- From what Dr. Blundell says in his lectures, (vide Lancet, for August, 30th, 1828, page 677,) he appears to think a mere visit dangerous. would serve to prove that ablution, change of clothes, chlorides, \&cc., are of some little avail.

Sixthly. That erysipelas may originate a mild form of puerperal fever, which may in its turn communicate a more malignant form. (In the two cases here alluded to, the symptoms in the commencement were nearly the same, the occurrence of dysuria in them both being some hat remarkable; the fatal difference was in their terminations, - typhus and death in the one, gradual recovery in the other.)

And, lastly, that a puerperal ferer, originating from a case of erysipelas, is not necessarily fatal.

I offer the above remarks with considerable diff. dence. The facts I have detailed may be relied on, and I leave the reader to found upon them what conclusions be may please.

\section{Hogsthorpe, Lincolnsbire,} February 12, 1848.

\section{CASE OF OVARIAN DISEASE.}

\section{By George Kennion, M.D., Harrogate.}

I was consulted by Mrs. W., the housekeeper in a family in this neighbourhood, a single woman, aged 34 ; on account of a large abdominal tumour, which she bad first perceived about two years previously, and which had gradually increased up to the present time, her size being that of a woman in the eighth month of pregnancy. There was little difficulty in ascertaining that this tumour was a large ovarian cyst, apparently unilocular. The catamenia had been absent for two years, but in every other respect her health was perfectly good. As ber case seemed appropriate for the operation of tapping, I advised her to have this operation performed, but to postpone it as long as she could possibly do so.

On the 15th of September I was requested to see her again, and found that the cyst had greatly increased in size. The abdominal parietes were exceedingly tense and thin, and she could neither walk, sit, nor lie down without the greatest discomfort, I therefore decided that the operation should be no longer postponed, and it was accordingly performed upon the 18th, with much tact, by my friend Mr. Beaumont, the usual attendant of the family. The fluid was of an oily consistence; the colour was remarkable, being almost as red as blood. Mrs. W. bore the operation (which was rendered more complicated by the presence of a second and smaller sac, which we could not detect until after the removal of the fluid from the principal sac,) exceedingly well; and, although we were not satisfied with the character of the fluid which was withdrawn, there was no reason to apprehend any untoward result.

I was sent for to see ber with Mr. Beaumont upon the evening of the 22nd, and found her with an exceedingly quick and weak thready pulse, an anxious haggard expression, constant jactitation, and complete anorexia. There had been no rigor. She had no pain 
nor tenderness in the abdomen, and the cyst was rapidly re-filling.

These symptoms continued gradually to increase in spite of tonics, stimulants, opium, and as generous a diet as she could be induced to take, and were succeeded by hiccough, vomiting, aphthæ on the tongue; and she sank upon the 28th, being just ten days after the operation.

The post-mortem examination, which was conducted by Mr. Beaumont, was very interesting. The two sacs which had been so recently emptied had re-filled, even to a greater extent than before the operation, the character of the fluid being similar to that which had been previously withdrawn. There were a very few flakes of lymph in the larger sac, but with this exception their lining membranes presented no unusual appearance. Behind these sacs was a large irregular nodulated tumour, extending from one iliac fossa to the other, and reaching as high as the last dorsal vertebra. This tumour consisted of an enormous congeries of smaller ovarian cysts, varying from the size of a filbert to that of a plover's egg. All these cysts were matted together, so that both ovaries were amalgamated as it vere into this large and shapeless mass, in the centre of which could be indistinctly traced the remains of the uterus, which by the constant pressure had been nearly absorbed. Each of these cysts contained a colourless fluid, of more or less consistence. The other organs of the body were quite bealthy.

Although no practical benefit could arise from the narrative of this case, it is so interesting in a pathological point of view, that $I$ have thought it right to place it upon record. Those who, like Mr. Safford Lee, are opposed to the operation of tapping in almost any case of ovariun dropsy, will probably consider that this case furnishes fresh support for their opinions; and indeed there can be but little doubt that the life of Mrs. W. might bave been prolonged a few weeks, had the operation not been performed; but it would have been, at the best, a question of weeks, for the walls of the larger cyst were so exceedingly thin, that it must soon bave ruptured, and our patient would in all probability have sunk under the tortures of acute peritonitis. On the other hand, with the healthy character of Mrs. W.'s constitution, and in the absence of other organic disease, there was every probability of her obtaining, with little risk, the relief which she sought. Indeed this case is one which, if it could be adduced as having any weight in a practical view, might serve as a beacon to those who are ever forward to advocate the removal of the ovarian sac; for no test could have discovered the existence of such extensive disease as the post.mortem examination of this case revealed to us; and had extirpation of the disease been attempted, how fearful the consequences must have been.

The treatment of ovarian dropsy is beset with so many difficulties, and, upon the whole, has been hitherto so unsucessful, that $I$ fear we must consider this disease as one of the opprobria medicina with which our science is encumbered. I have never seen (and in this I am borne out by the highest authorities) any benefit arise from the use of medicine. Iodine I have tried, and have seen tried, with no good result whatever. Mercury is worse than useless. We can look for no assistance from purgatives or diuretics. What then remains to be done? In the first instance I would always recommend that the fluid be withdrawn, unless there existed any peculiarity in the case to forbid even this minor operation. When this has been done, I have the abdomen tightly bandaged, and this, we are told, will sometimes produce a radical cure. I have been so unfortunate as only to witness one case where this object has been accomplished. I have frequently seen it fail. The experience of others, however, upon whose reports the utmost reliance may be placed, is so far in favour of this plan, that $I$ would always adopt it where it is practicable.

In one case which $I$ attended in July, the bandage was tightly drawn over the abdomen in the course of two or three days after the fluid had been removed; but the effect of this was so much obstruction to the passage through the ascending vena cava, that cedema of the legs to the most frightful extent was induced before the termination of a week, and $I$ was obliged to discontinue the bandage altogether. Of course, after the operation of tapping, care must be taken to keep up a regular but gentle action, both of the bowels and the kidneys; beyond this, the less we interfere with medicine the better.

If the sac rapidly re-fills after the first or second operation, I think we are justified in recommending the more formidable operation of extirpating the ovary, provided that no other organic disease exists; but if the return of the disease is slow, and occupies many months, or a year or more, the danger to the patient is, I think, so trifling, as long as this state of things continues, that it would be wrong, in my opinion, to perform so hazardous an operation.

\section{BUCHU IN DROPSY.}

TO THE EDITOR OF THE PROVINCIAL MEDICAL AND SIR,

Observing in your Journal of Norember 3rd, a communication from "A Member," strongly adrocating the efficacy of "Diosma crenata," in some dropsical affections, and having shortly after two cases, one of ascites dependent upon a disordered state of the liver, and the other scarlatinal dropsy, I was induced to make a triul of the buchu, and I am bappy to say, with good effect. It is not the first time $I$ have seen the beneficial use of buchu, but as I believe it is not now so much in fashion as formerly, I herewith send you a history of the cases, and as a member of the Association, (if you think them worthy a place in the Journal,) I shall feel obliged by their insertion.

I ain, Sir, yours \&c.,

EDWARD HOSKINS, M.R.C.S.E., \&c.

Loughborough, Dec. 12, 1817.

\section{Case I.}

November 8th, 1847. Mrs. M., aged 47, of dyspeptic habit, has been suffering for some days past from pain. 